\title{
Hypertonic Saline and PEP: Is It Worth a Try?
}

Cystic fibrosis (CF) is a recessive genetic disease that requires aggressive therapies to slow the disease progression. CF is a complex disorder that primarily affects the digestive system and the lungs. A major characteristic of $\mathrm{CF}$ is lung disease, which is responsible for the majority of CF-related deaths.

$\mathrm{CF}$ is caused by an absent or deficient CF transmembrane regulator, which is a protein responsible for chloride secretion. This ion-transport abnormality causes a progressive loss of lung function, with a cascading pathophysiology that creates a vicious cycle in which the airways suffer dehydration, mucus retention, obstruction, inflammation, and infection. Current $\mathrm{CF}$ respiratory therapies aim to break the cycle and treat the symptoms.

The Cystic Fibrosis Foundation is committed to finding a cure for $\mathrm{CF}$ - a therapy that actually targets the basic genetic defect, and the Foundation's CF Therapeutics Development Network has several clinical trials underway. ${ }^{1}$ However, the mantra in CF research and care is to leave no stone unturned. In other words, any and all possible therapeutic approaches to fight this disease are considered for research and discovery, including medications already available on the market. Investigating and hopefully discovering the usefulness of medications already available is referred to as the "low-hanging fruit."

Hypertonic saline is one of the low-hanging fruits studied in CF. In Australia it was noticed that surfers with CF had better outcomes than non-surfers. The hypothesis was that the salty mist inhaled during surfing helps clear the airways through osmosis-that the inhaled salt allowed more water into the airways and increased the airway surface liquid. This hypothesis prompted investigation, and studies did indeed show improved mucociliary transport. ${ }^{2,3}$ To date, the largest study of hypertonic saline in $\mathrm{CF}$, by Elkins et al, ${ }^{4}$ was a multicenter study in patients with $\mathrm{CF}$ who inhaled $7 \%$ hypertonic saline twice daily. The therapy significantly decreased the incidence of pulmonary exacerbations and moderately improved pulmonary function. As a result of those studies, inhaled hypertonic saline therapy is now recommended by the Cystic Fibrosis Foundation as a maintenance therapy for patients with $\mathrm{CF}$ who are $\geq 6$ years old, and there is a study in process with children younger than 6 years. ${ }^{5}$

Unfortunately, not everyone can tolerate hypertonic saline therapy. Some patients experience substantial bron- chospasm, and in those patients hypertonic saline is not recommended. Furthermore, in those who can tolerate it there is the concern that inhaling $4 \mathrm{~mL}$ of hypertonic saline twice daily adds an additional $30 \mathrm{~min}$ of therapy to an already time-consuming daily treatment regimen. With respect to hypertonic saline therapy, it boils down to the question of toleration and/or adherence, which is why the data from O'Connell and colleagues ${ }^{6}$ in this issue of the Journal are so intriguing. They studied a positive expiratory pressure (PEP) nebulizer to deliver hypertonic saline to 4 patients who previously could not tolerate hypertonic saline via a traditional nebulizer, due to bronchospasm, bad taste, and intolerable cough. All 4 patients tolerated and adhered to hypertonic saline via PEP nebulizer, and there was a trend toward fewer pulmonary exacerbations and longer time between exacerbations. These results are impressive.

See the Original Study on Page 771

O'Connell and colleagues thought outside the box. The study, albeit a small case series, is motivating and thought provoking. The patients appear to have benefited from the PEP therapy, with bronchodilation, reduced bronchospasm, and improved aerosol deposition. Interestingly, in an editorial on hypertonic saline therapy, Ratjen mentioned concern about inhaled hypertonic saline not reaching the small airways where the mucus plugging is causing obstruction. ${ }^{7}$ Perhaps PEP therapy with hypertonic saline is the answer! Why not try this technique the next time you challenge a patient who previously showed a $15 \%$ decline in pulmonary function, or hated the taste, or could not tolerate the excessive cough after taking hypertonic saline via nebulizer alone? It seems more than worthy of a try, in light of the potential benefits of hypertonic saline therapy. Furthermore, what if one was to actually perform PEP therapy while taking the hypertonic saline? Perhaps combining the therapies will boost adherence, as well as benefit.

Catherine A O'Malley RRT Respiratory Care Department Children's Memorial Medical Center Chicago, Illinois 


\section{Hypertonic Saline and PEP: Is It Worth a Try?}

\section{REFERENCES}

1. Cystic Fibrosis Foundation Therapeutics Development Network. Drug developmentpipeline.http://www.cff.org/research/DrugDevelopment Pipeline. Accessed April 12, 2011.

2. Eng PA, Morton J, Douglass JA, Riedler J, Wilson J, Robertson CF. Short-term efficacy of ultrasonically nebulized hypertonic saline in cystic fibrosis. Pediatr Pulmonol 1996;21(2):77-83.

Ms O'Malley has disclosed relationships, with Pari, Pharmaxis, and Gilead.

Correspondence: Catherine A O'Malley RRT, Respiratory Care Department, Children's Memorial Medical Center, 2300 Children's Plaza, Box 58, Chicago IL 60614. E-mail: comalley@ childrensmemorial.org.

DOI: $10.4187 /$ respcare. 01358
3. Donaldson SH, Bennett WD, Zeman KL, Knowles MR, Tarran R, Boucher RC. Mucus clearance and lung function in cystic fibrosis with hypertonic saline. N Engl J Med 2006;354(3):241-250.

4. Elkins MR, Robinson M, Rose BR, Harbour C, Moriarty CP, Marks GB, et al; National Hypertonic Saline in Cystic Fibrosis (NHSCF) Study Group. A controlled trial of long-term inhaled hypertonic saline in patients with cystic fibrosis. N Engl J Med 2006;354(3): 229-240.

5. Flume P, O'Sullivan BP, Robinson KA, Goss CH, Mogayzel PJ Jr, Willey-Courand DB, et al; Cystic Fibrosis Foundation Pulmonary Therapies Committee. Cystic fibrosis pulmonary guidelines: chronic medications for maintenance of lung health. Am J Crit Care Med 2007;176(10):957-969.

6. O'Connell OJ, O'Farrell C, Harrison MJ, Eustace JA, Henry MT, Plant BJ. Nebulized hypertonic saline via positive expiratory pressure versus via jet nebulizer in patients with severe cystic fibrosis. Respir Care 2011;56(6):771-775.

7. Ratjen F. Restoring airway surface liquid in cystic fibrosis. N Engl J Med 2006;354(3):291-293. 